OPEN ACCESS

Edited by:

Erna Geessien Kroon, Federal University of Minas Gerais,

Brazil

Reviewed by:

Susanne M. Krug,

Charité - Universitätsmedizin Berlin,

Germany

Gefen Yin,

Yunnan Agricultural University, China

*Correspondence:

Philippe V. Afonso

philippe.afonso@pasteur.fr

Specialty section: This article was submitted to Virology,

a section of the journal

Frontiers in Microbiology

Received: 24 July 2021

Accepted: 23 August 2021

Published: 20 September 2021

Citation:

Zoladek J, Legros V, Jeannin $P$, Chazal M, Pardigon N, Ceccaldi P-E,

Gessain A, Jouvenet $N$ and Afonso PV (2021) Zika Virus Requires

the Expression of Claudin-7 for

Optimal Replication in Human Endothelial Cells.

Front. Microbiol. 12:746589.

doi: 10.3389/fmicb.2021.746589

\section{Zika Virus Requires the Expression of Claudin-7 for Optimal Replication in Human Endothelial Cells}

\author{
Jim Zoladek ${ }^{1}$, Vincent Legros ${ }^{1,2}$, Patricia Jeannin ${ }^{1}$, Maxime Chazal $^{3}$, Nathalie Pardigon $^{4}$, \\ Pierre-Emmanuel Ceccaldi ${ }^{1}$, Antoine Gessain ${ }^{1}$, Nolwenn Jouvenet ${ }^{3}$ and \\ Philippe V. Afonso ${ }^{1 *}$
}

${ }^{1}$ Unité Épidémiologie et Physiopathologie des Virus Oncogènes, Institut Pasteur, Centre National de la Recherche Scientifique UMR 3569, Université de Paris, Paris, France, ${ }^{2}$ VetAgro Sup, Centre International de Recherche en Infectiologie (CIRI), Lyon, France, ${ }^{3}$ Unité Signalisation Antivirale, Institut Pasteur, Centre National de la Recherche Scientifique UMR 3569 , Paris, France, ${ }^{4}$ Groupe Arbovirus, Unité Environnement et Risques Infectieux, Institut Pasteur, Paris, France

Zika virus (ZIKV) infection has been associated with a series of neurological pathologies. In patients with ZIKV-induced neurological disorders, the virus is detectable in the central nervous system. Thus, ZIKV is capable of neuroinvasion, presumably through infection of the endothelial cells that constitute the blood-brain barrier (BBB). We demonstrate that susceptibility of BBB endothelial cells to ZIKV infection is modulated by the expression of tight-junction protein claudin-7 (CLDN7). Downregulation of CLDN7 reduced viral RNA yield, viral protein production, and release of infectious viral particles in several endothelial cell types, but not in epithelial cells, indicating that CLDN7 implication in viral infection is cell-type specific. The proviral activity of CLDN7 in endothelial cells is ZIKV-specific since related flaviviruses were not affected by CLDN7 downregulation. Together, our data suggest that CLDN7 facilitates ZIKV infection in endothelial cells at a post-internalization stage and prior to RNA production. Our work contributes to a better understanding of the mechanisms exploited by ZIKV to efficiently infect and replicate in endothelial cells and thus of its ability to cross the BBB.

Keywords: flavivirus, Zika virus, claudin, endothelial cells, infection, blood-brain barrier

\section{INTRODUCTION}

Zika virus (ZIKV) is an arbovirus from the Flaviviridae family, which was first isolated in Uganda in 1947 (Dick et al., 1952). It was initially disregarded as only sporadic and mild cases were reported. With the virus outbreaks in the Pacific Islands and the Americas in 2015, ZIKV received widespread attention. These outbreaks were associated with neurological pathologies, such as Guillain-Barré syndrome (Cao-Lormeau et al., 2016), congenital microcephaly (Cauchemez et al., 2016), meningoencephalitis (Carteaux et al., 2016), and myelitis (Mecharles et al., 2016). During ZIKV-induced neurological disorders, the virus is detected in the central nervous system (CNS), and viral RNA can be amplified from the cerebrospinal fluid of infected patients (Roze et al., 2016).

In normal condition, the CNS is protected from blood-borne pathogens by the bloodbrain barrier (BBB), a structure composed of astrocytes, pericytes, microglia cells, a basal 
membrane, and a continuous endothelium with tight junctions (Ballabh et al., 2004; Obermeier et al., 2016). In order to penetrate the CNS, ZIKV must cross the BBB. ZIKV infection induces $\mathrm{BBB}$ disruption in the later stages of the disease (Leda et al., 2019), as evidenced by fibrinogen diffusion into the CNS parenchyma (Panganiban et al., 2020) and neuroinvasion of infected monocytes (Ayala-Nunez et al., 2019; de Carvalho et al., 2019). However, during early ZIKV infection stages, the BBB remains intact. This is also the case during infection with other flaviviruses (Mustafa et al., 2019), where neuroinvasion occurs by transcytosis or productive infection of endothelial cells (Bramley et al., 2017; Mladinich et al., 2017; Papa et al., 2017; Cle et al., 2020).

Zika virus has a broad tropism for human cell types. ZIKV enters cells by endocytosis in a $\mathrm{pH}$-dependent manner. The factors favoring ZIKV entry is not well defined. Adsorption of the virus at the cell surface is mediated through heparan sulfate proteoglycans (HSPG) and C-type lectin receptors interaction (Hamel et al., 2015; Kim et al., 2017). Endocytosis might involve apoptotic mimicry, as previously suggested for the related dengue virus (DENV; Amara and Mercer, 2015). In vitro, ZIKV endocytosis is mediated through recognition of phosphatidylserines present on the viral envelope by members of the TAM family (i.e., TYRO3, AXL, and MER) or TIM-1 receptor (Hamel et al., 2015; Meertens et al., 2017; Dejarnac et al., 2018). Although in vitro AXL depletion or the use of anti-AXL antibodies rendered cells resistant to infection (Liu et al., 2016; Meertens et al., 2017), in vivo AXL (or members of the TAM family) knock-out in $\mathrm{IFNAR}^{-1-}$ mice had no significant effect on these mice susceptibility to ZIKV infection (Hastings et al., 2017; Wang et al., 2017). The current model suggests that the AXL-dependent signaling inhibits the antiviral interferon (IFN) response, thereby promoting viral replication (Chen et al., 2018). Other factors have been proposed to act as cell-type specific receptors for ZIKV, such as, for example, integrin $\alpha \mathrm{V} \beta 5$ and NCAM1 in neural stem cells (Srivastava et al., 2020; Wang et al., 2020).

Claudins (CLDNs) are a large family of transmembrane proteins involved in cell-to-cell or cell-to-substrate interactions (Krause et al., 2008). They participate in the formation of tight junctions and are therefore key components of physiological barriers. Upon flavividae infection, BBB and TJ are often disrupted: infection with West Nile virus and classic swine fever virus both lead to claudin-1 degradation (Medigeshi et al., 2009; Roe et al., 2012; Wang et al., 2021) and Japanese encephalitis virus infection induces the degradation of claudin-5 (Chang et al., 2015). Claudins can also directly participate in viral infection (Colpitts and Baumert, 2017). Within the Flaviviridae family, dengue viruses use CLDN1 as a receptor in hepatocytes (Coller et al., 2009; Gao et al., 2010) and hepatitis C virus (HCV) exploits CLDN1, 6, and 9, as receptors in hepatocytes (Evans et al., 2007; Meertens et al., 2008).

Herein, we studied the susceptibility of BBB endothelial cells to ZIKV infection and identified CLDN7 as a key proviral factor in endothelial cells.

\section{MATERIALS AND METHODS}

\section{Cell Lines}

Human kidney epithelial HEK 293T (ATCC, CRL-11268), human lung epithelial A549 (ATCC, CCL-185), and African green monkey kidney epithelial Vero E6 (ATCC, CRL-1586) cells were maintained in high-glutamine and high-glucose DMEM (Thermo fisher) supplemented with $10 \%$ fetal bovine serum (FBS; Thermo fisher), $100 \mathrm{U} / \mathrm{ml}$ penicillin and $100 \mu \mathrm{g} /$ $\mathrm{ml}$ streptomycin (Thermo fisher). Aedes albopictus C6/36 (ATCC, CRL-1660) cells were maintained in Leibovitz's L-15 medium (Thermo fisher) supplemented with 10\% FBS. Transformed human bone marrow endothelial cells TrHBMEC (Schweitzer et al., 1997), human cerebral microvascular endothelial cells (hCMEC/D3; Merck, SCC066), and primary human umbilical vein endothelial cells HUVEC (ATCC, CRL-1730) cells were maintained in complete EndoGRO Basal Medium (Merck) supplemented with 5\% FBS, 0.2\% EndoGRO-LS supplement, $5 \mathrm{ng} / \mathrm{ml}$ rhEGF, $10 \mathrm{mM}$ L-glutamine, $1 \mu \mathrm{g} / \mathrm{ml}$ hydrocortisone hemisuccinate, $0.75 \mathrm{U} / \mathrm{ml}$ heparan sulphate, and $50 \mu \mathrm{g} / \mathrm{ml}$ ascorbic acid (Merck). Alternatively, hCMEC/D3 cells have been maintained in EBM-2 basal medium (Lonza) supplemented with $5 \%$ FBS, $1.5 \mu \mathrm{M}$ hydrocortisone (Merck), $5 \mu \mathrm{g} / \mathrm{ml}$ ascorbic acid (Merck), 1\% chemically defined lipid concentrate (Thermo fisher), $1 \mathrm{ng} / \mathrm{ml}$ human bFGF (Merck), $10 \mu \mathrm{M}$ HEPES (Thermo fisher), and antibiotics. This culture condition was used when compared to EndoGRO media. All cells were kept at $37^{\circ} \mathrm{C}$ with $5 \% \mathrm{CO}_{2}$ except for $\mathrm{C} 6 / 36$ which were kept at $28^{\circ} \mathrm{C}$ with no $\mathrm{CO}_{2}$.

\section{Viruses}

Two strains of ZIKV were used in this study: the AF/1991/ HD78788 strain (GenBank: KF383039) obtained in Senegal in 1991, which belongs to the African lineage, and the Brazil/2016/ INMI1 strain (GenBank: KU991811) isolated during the 2016 outbreak in Brazil, which belongs to the Asian lineage. Japanese encephalitis virus JEV/G3/RP-9 (Liang et al., 2009) and yellowfever vaccine strain YFV/17D (GenBank: MG051217) were used as controls, as they are closely related to ZIKV. Virus stocks were produced in C6/36 cells. All infections were performed in 2\% FBS media in BSL-3 facilities.

\section{Gene Knockdown}

Gene knockdown was performed using lentiviral vectors carrying shRNA. To produce these lentiviral vectors, HEK 293T cells were co-transfected with psPAX2 (encoding HIV Gag/Pol, $4.68 \mu \mathrm{g}$; Addgene: 12260), pMD2.G [vesicular stomatitis virus G protein (VSV-G), $2.52 \mu \mathrm{g}$; Addgene: 12259], and pLKO.1 encoding the shRNA (TRC-Hs1.0 library, $9 \mu \mathrm{g}$, GE Dharmacon). Transfection was performed using LipoD-293 transfection reagent (Sinagen) according to the manufacturer's recommendations. After $72 \mathrm{~h}$, supernatants were collected, centrifuged, and stored at $-80^{\circ} \mathrm{C}$.

Cells were exposed for $2 \mathrm{~h}$ to the lentivirus-containing medium, and gene expression was allowed for $48 \mathrm{~h}$ then transduced cells were selected with $1 \mu \mathrm{g} / \mathrm{ml}$ Puromycin (Merck) 
for 2 weeks. The obtained culture is thus a mix population of transduced cells.

\section{Microarray Analysis}

Biotinylated single strand cDNA targets were prepared, starting from $250 \mathrm{ng}$ of total RNA, using the Ambion WT Expression Kit (Cat \# 4411974) and the Affymetrix GeneChip ${ }^{\circledR}$ WT Terminal Labeling Kit (Cat \# 900671) according to Affymetrix recommendations. Following fragmentation and end-labeling, $3 \mu \mathrm{g}$ of cDNAs were hybridized for $16 \mathrm{~h}$ at $45^{\circ} \mathrm{C}$ on GeneChip ${ }^{\circledR}$ Human Gene 2.0 ST arrays (Affymetrix) interrogating over 400,000 RefSeq transcripts and $\sim 11,000$ LncRNAs. The chips were washed and stained in the GeneChip $^{\circledR}$ Fluidics Station 450 (Affymetrix) and scanned with the GeneChip ${ }^{\circledR}$ Scanner 3000 7G (Affymetrix) at a resolution of $0.7 \mu \mathrm{m}$. Raw data (CEL Intensity files) were extracted from the scanned images using the Affymetrix GeneChip $^{\circledR}$ Command Console (AGCC) version 4.1.2. CEL files were further processed with Affymetrix Expression Console software version 1.4.1 to calculate probe set signal intensities using Robust Multi-array Average (RMA) algorithms with default settings. Data have been loaded into Array Express, accession number E-MTAB-10813.

\section{Gene Expression Analysis}

Cellular RNA was extracted using the RNeasy Plus Mini Kit (Qiagen), quantified (Nanodrop ND-1000) and $500 \mathrm{ng}$ was reverse-transcribed using the SuperScript II Reverse Transcriptase (Thermo fisher) and random hexamer primers (Eurobio) with the following cycle: $2 \mathrm{~min}$ at $95^{\circ} \mathrm{C} ; 90 \mathrm{~min}$ at $42^{\circ} \mathrm{C}$; and $15 \mathrm{~min}$ at $70^{\circ} \mathrm{C}$ (GeneAmp PCR System 9700, Applied Biosystems). SYBR Green RT-qPCR was performed on $25 \mathrm{ng}$ of complementary DNA with iTaq Universal SYBR Green Supermix (Biorad) using primers listed in Supplementary Table 1 with the following protocol: $15 \mathrm{~min}$ at $95^{\circ} \mathrm{C}$ followed by 40 cycles consisting of $15 \mathrm{~s}$ at $95^{\circ} \mathrm{C}, 20 \mathrm{~s}$ at $60^{\circ} \mathrm{C}$, and $30 \mathrm{~s}$ at $72^{\circ} \mathrm{C}$ (Mastercycler ep Realplex Thermal Cycler, Eppendorf). The melting curve was also obtained to control the amplified product. Relative expression was analyzed using the $-\Delta \Delta C_{\mathrm{T}}$ method.

Functional enrichment analysis of the differentially expressed genes was performed using FunRich 3.1.3 (Pathan et al., 2015).

\section{Western Blot Analysis}

Cells were lysed using RIPA buffer (Merck) containing protease inhibitor cocktail (Merck) for $15 \mathrm{~min}$ on ice. Cellular debris were not pelleted since claudins often accumulate in the insoluble fraction. Whole cell lysates were heat-denatured $70^{\circ} \mathrm{C}$ for $10 \mathrm{~min}$ in LDS Sample Buffer and $500 \mathrm{mM}$ DTT (Novex). Proteins were resolved on NuPAGE $4-12 \%$ Bis Tris gel (Novex) in MOPS buffer and were transferred to nitrocellulose membranes (Trans Blot Turbo, Biorad). Blocking followed by immunoblotting was performed on an iBind Flex Western Device (Thermo fisher) using antibodies listed in Supplementary Table 2 according to the manufacturer's recommendations.

\section{Viral Titration Assay}

Supernatants were sequentially diluted 10-fold and inoculated onto Vero E6 monolayers in 24-well plates. After $1 \mathrm{~h}$ incubation, $2 \%$ carboxymethyl cellulose (CMC; Merck) overlay containing $2 \%$ FBS culture medium was added to each well. For fociformation assays, plates were then incubated at $37^{\circ} \mathrm{C}$ for $72 \mathrm{~h}$. Following the incubation, CMC overlay was removed and a PBS - paraformaldehyde 4\% (Electron Microscopy Sciences) solution was added into each well and incubated at room temperature for $15 \mathrm{~min}$. Fixation solution was removed and plates were washed three times with PBS. Cells were then permeabilized with PBS - Triton $0.2 \%$ for $3 \mathrm{~min}$, washed three times, and incubated in blocking buffer (PBS - Tween 20 $0.1 \%$ - FBS $1 \%$ ) for $30 \mathrm{~min}$ followed by $2 \mathrm{~h}$ incubation with pan-Flavivirus antibody 4G2 purified from the ATCC hybridoma. Plates were washed three times with PBS followed by an hourlong incubation with a secondary antibody conjugated to horseradish peroxidase (Biorad). Detection was achieved using the VIP Peroxidase Assay (Vector) according to the manufacturer's recommendations. Titer is expressed as foci-forming units (FFU).

Alternatively, for plaque-formation assays, plates were incubated at $37^{\circ} \mathrm{C}$ for 5 days after adding the CMC overlay. They were then washed and fixed as described earlier. Plates were stained with a $1 \%$ crystal violet solution (Merck). Titer is expressed as plaque-forming units (PFU).

\section{Replication Assay}

Infected cells were washed with PBS, and cellular RNA was extracted using the Nucleospin 96 RNA kit (Macherey Nagel). One-step RT-qPCR was performed using the Power SYBR Green RNA-to- $C_{\mathrm{T}}$ kit (Thermo fisher) with the following protocol: $30 \mathrm{~min}$ at $48^{\circ} \mathrm{C}, 10 \mathrm{~min}$ at $95^{\circ} \mathrm{C}$ followed by 40 cycles consisting of $15 \mathrm{~s}$ at $95^{\circ} \mathrm{C}$, and $1 \mathrm{~min}$ at $60^{\circ} \mathrm{C}$ (QuantStudio 6 Flex RealTime PCR System, Applied Biosystems). The melting curve was also obtained. Genome equivalent (GE) concentration was assessed with the standard curve method using known concentrations of synthetic RNA fragments corresponding to the ZIKV NS5 coding region and was normalized to GAPDH level.

\section{Binding and Internalization Assay}

Cells were seeded in $2 \%$ FBS medium $24 \mathrm{~h}$ prior to infection. Pre-chilled cells were incubated with ZIKV (multiplicity of infection - MOI 1 and 10) for $1 \mathrm{~h}$ at $4^{\circ} \mathrm{C}$ to block the internalization of the viruses. The cells were then washed three times with cold PBS to remove unbound particles. Cell surface adsorbed ZIKV particles was analyzed by harvesting RNA at this step. ZIKV internalization was induced by adding warm medium and keeping the cells at $37^{\circ} \mathrm{C}$ for $2 \mathrm{~h}$. The cells were then treated with trypsin (Thermo fisher) to remove un-internalized particles, cells were pelleted, and RNA was harvested.

\section{Immunofluorescence}

Cells were fixed with $4 \%$ paraformaldehyde (PFA; Sigma-Aldrich) for $30 \mathrm{~min}$ at room temperature, permeabilized with $0.5 \%$ Triton $\mathrm{X}-100$ in PBS, and then blocked with PBS containing $0.05 \%$ 
Tween and 5\% BSA before incubation with the anti-NS1 17A12 antibody (Schul et al., 2007). Antibody labeling was revealed with Alexa Fluor 488-conjugated antibody. Coverslips were mounted on slides using ProLong Gold Antifade reagent with NucBlue solution (Invitrogen). Images were acquired with a Zeiss LSM 700 inverted confocal microscope.

\section{Quantification and Statistical Analysis}

Specific statistical tests used to analyze experimental datasets are described in the respective figure legends. Graphical representations and statistical analyses were performed using GraphPad Prism version 8.2 for MacOS (GraphPad Software). Nonparametric tests were used, as we could not ascertain that the hypothesis for parametric tests were fulfilled. When comparing cells in the different media (Figure 1 and Supplemental Figures 1, 2), two-way ANOVA (followed by Sidak's post-hoc tests) or the Mann-Whitney and Kruskal-Wallis tests were used (data are unpaired). When comparing the knockdown, we considered paired tests as a single batch of cells was transduced with the different shRNAs, and a new batch was used for each replicate. Therefore, two-way ANOVA (followed by Sidak's post-hoc tests) or Friedman tests (followed by Dunn's post-hoc tests) were used. Values of $p$ indicated in figure legends corresponds to ANOVA result.

\section{RESULTS}

\section{The Susceptibility of hCMEC/D3 Cells to ZIKV Infection Depends on the Culture Medium}

The human cerebral microvascular endothelial cell line hCMEC/ D3 is a widely used model for in vitro human BBB studies (Weksler et al., 2005). Since ZIKV neuroinvasion relies on a productive infection of BBB endothelial cells (Liu et al., 2016; Mladinich et al., 2017; Papa et al., 2017; Richard et al., 2017; Cle et al., 2020), we examined the susceptibility to ZIKV infection of hCMEC/D3 cells.

We confirmed using RT-qPCR analysis that hCMEC/D3 cells can be productively infected with an African ZIKV strain (Figures 1A,B). The cells released infectious particles (Figures 1C,D), indicating that a complete viral replication cycle. Intriguingly, we found a difference in infection efficiency that was dependent on the cell culture medium, both in terms of viral RNA yield and production of infectious particles (Figure 1, EndoGRO vs. EBM-2). Differences were more marked at a lower MOI (Figures 1A,C vs. Figures 1B,D). Similar differences in viral susceptibility were observed with a Brazilian ZIKV strain (belonging to the Asian lineage), at $72 \mathrm{~h}$ postinfection (Figures 1E,F).

Our first hypothesis was that factors present in the medium could interfere with viral infectivity. To test this, we suspended the viral stock in one or the other medium (or in DMEM as a control) and the inoculum was let to adsorb for $2 \mathrm{~h}$ on hCMEC/D3 (previously cultured in EndoGRO). Cells were then washed and cultured in EndoGRO for $48 \mathrm{~h}$. RT-qPCR analysis performed at $48 \mathrm{~h}$ post-infection revealed that the levels of intracellular viral RNA were similar in the three conditions (Supplementary Figure 1). This suggests that the culture media does not alter the cell-virus interaction per se. The differential susceptibility observed in the two culture conditions likely depend on differential gene expression.

We cultured hCMEC/D3 cells in EndoGRO or in EBM-2 prior to infection. Infection and subsequent culture were then performed in DMEM. We found that viral replication efficacy was dependent on the medium in which the cells were initially cultured (Supplementary Figure 2). This suggests that the cells, while being cultured in the different media, have acquired intrinsic differences to ZIKV infection susceptibility.

\section{Cells Cultured in EndoGRO Overexpress Claudin-7 When Compared to Cells Cultured in EBM-2}

First, we examined whether hCMEC/D3 cells cultured in the two media differentially expressed AXL and other members of the TAM family (i.e., TYRO3 and MER), which have been found to regulate endothelial susceptibility to ZIKV (Liu et al., 2016; Richard et al., 2017). Western blot analysis revealed that AXL expression remained unchanged in either medium (Figure 2A). Similarly, we did not see any significant difference in the expression of $A X L$ at the mRNA level (Figure 2B). While TYRO3 and MER proteins are not detectable by western blot in hCMEC/D3 cells, we found that the mRNA levels of TYRO3 and MER were comparable in both media (Figure 2B).

We compared the transcriptome of hCMEC/D3 cells cultured in EBM-2 and in EndoGRO to identify cellular genes that could account for differences in susceptibility. Microarray analysis showed that the expression of most genes was left unchanged in the two conditions, at the exception of 101 genes, which were upregulated in cells cultured in EBM-2 as compared to cells cultured in EndoGRO, and of 38 genes that were upregulated in cells cultured in EndoGRO as compared to EBM-2 cultured cells (Figure 2C and Supplementary Tables 3 and 4).

Among the proteins expressed at higher level in EndoGRO medium than in EBM-2, we identified Claudin-7 (CLDN7). This gene caught our attention as claudins have been identified as modulators of cellular sensitivity to viruses from the Flaviviridae family (Colpitts and Baumert, 2017). The endogenous protein expression levels of CLDN7 could not be detected at the protein level in endothelial cells, as previously reported (Vu et al., 2009; Supplementary Figure 3). It was, however, detected in A549 and HEK 293T epithelial cells. Of note, CLDN7 could only be detected when analyzing whole cell lysates (i.e., non-centrifuged, comprising the insoluble fraction). RT-qPCR analysis confirmed that CLDN7 mRNA abundance increased in cells grown in EndoGRO when compared to cells cultured in EBM-2 (Figure 2D), consistent with the microarray analysis. In contrast, the mRNA levels of CLDN5 and CLDN3 - the other predominant claudins expressed in hCMEC/D3 cells (Weksler et al., 2005; Vu et al., 2009; Schrade et al., 2012; Urich et al., 2012) - were unchanged. Of note, at the 

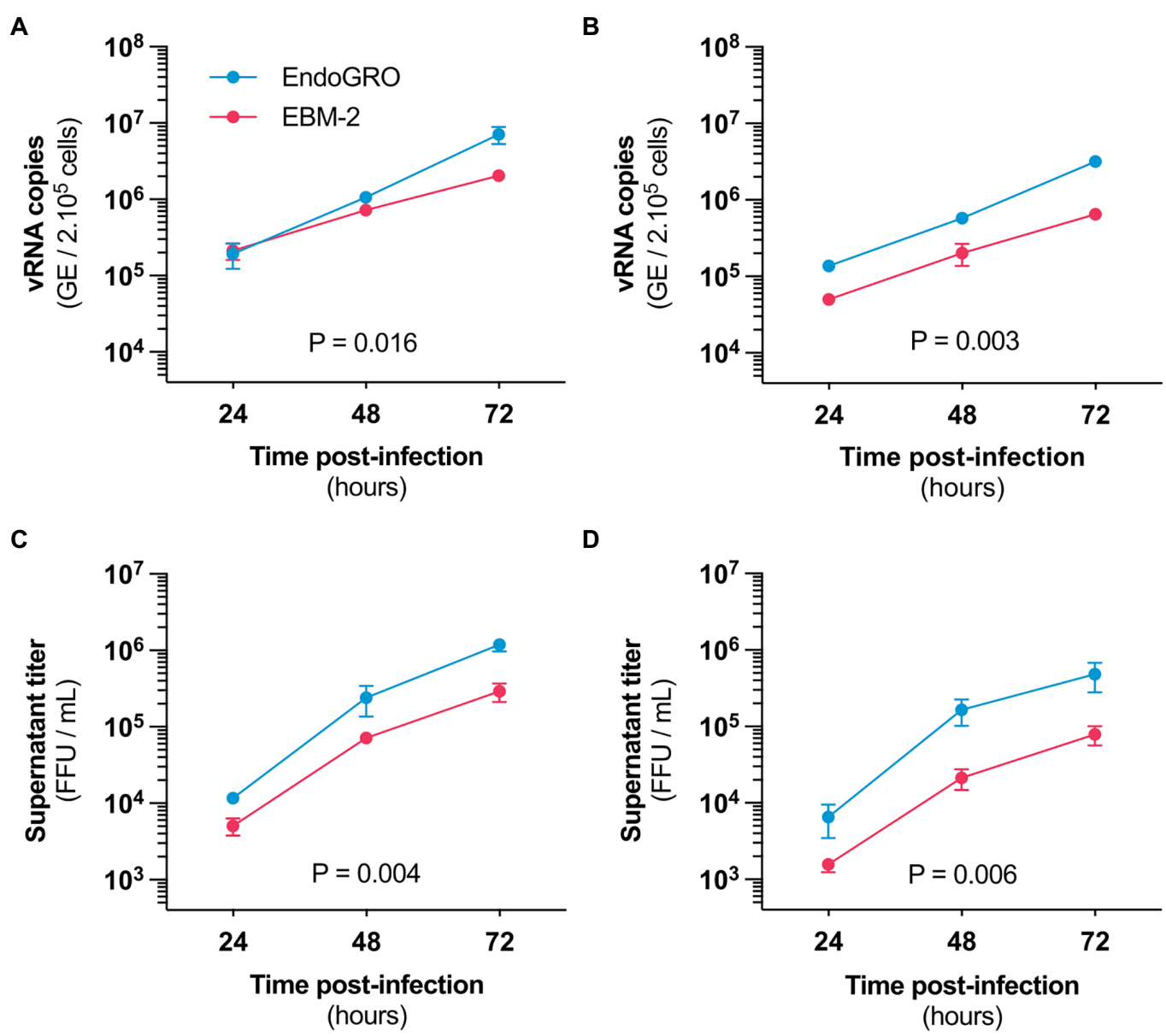

D
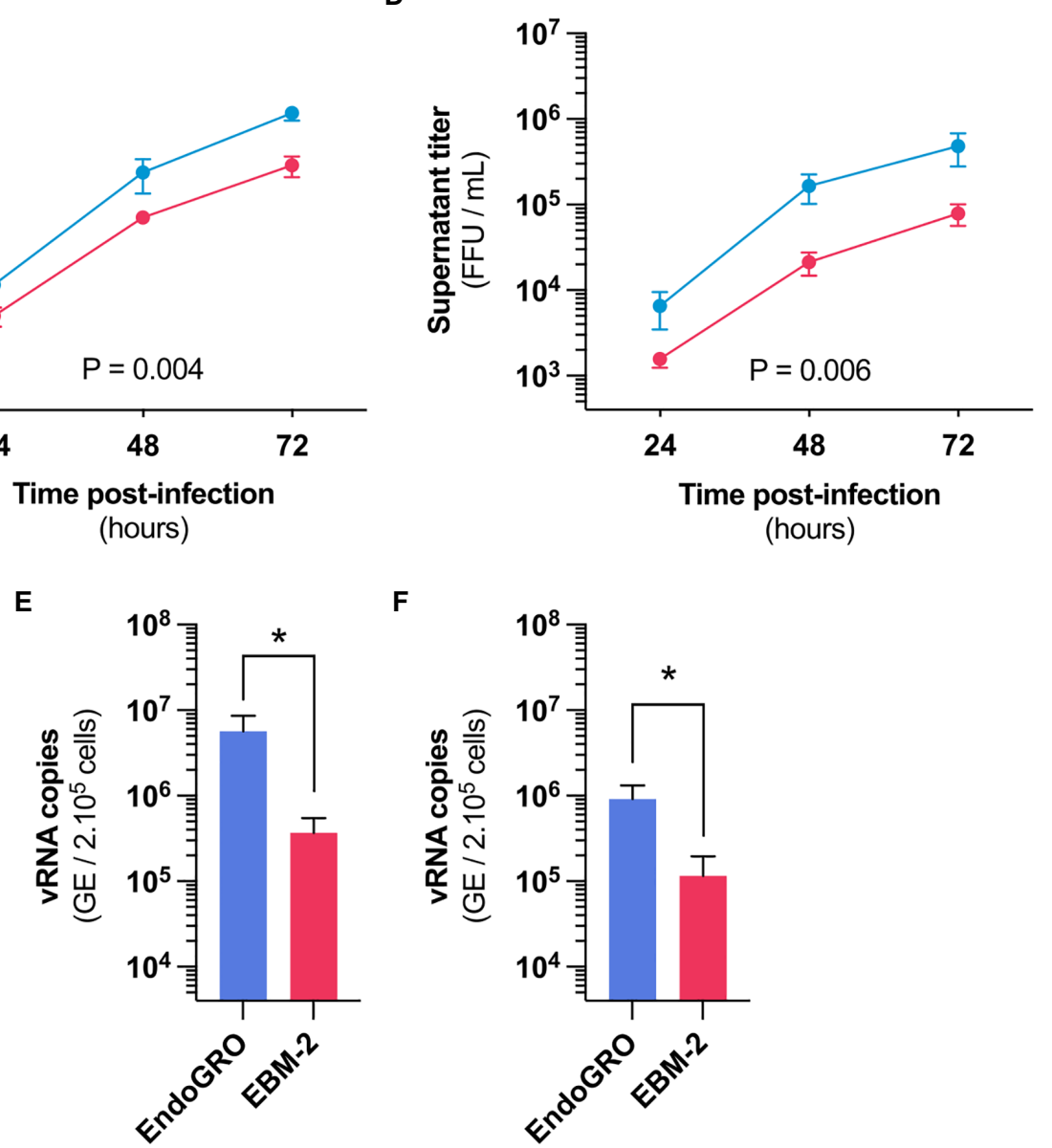

FIGURE 1 | Culture medium alters hCMEC/D3 susceptibility to Zika virus (ZIKV) infection. (A,B) Time-course quantification of viral RNA through RT-qPCR in hCMEC/D3 cells cultured in EBM-2 (red) or EndoGRO (blue) and infected with the African HD78788 ZIKV strain. (A) Cells were infected at a MOI of 1 ( $n=4$ independent experiments). (B) Cells were infected at a $\mathrm{MOI}$ of 0.1 ( $n=3$ independent experiments). (C,D) Time-course quantification of viral production in the supernatant of hCMEC/D3 cells cultured in EBM-2 (red) or EndoGRO (blue) and infected with the African HD78788 ZIKV strain. (C) Cells were infected at a MOI of 1 ( $n=4$ independent experiments). (D) Cells were infected at a MOI of 0.1 ( $n=3$ independent experiments). (E,F) Quantification at $72 \mathrm{~h}$ post-infection of viral RNA through RT-qPCR in hCMEC/D3 cells cultured in EndoGRO or EBM-2 and infected with the Brazilian INMI1 ZIKV strain. (E) Cells were infected at a MOI of 1 ( $n=3$ independent experiments). (F) Cells were infected at a MOI of 0.1 ( $n=3$ independent experiments). For each sample point, the experiment was performed in triplicate (each data point is the mean of three wells). Experiments were performed three or four times, as indicated. Data are presented as mean \pm SEM. Statistical significance was obtained using 2-Way ANOVA tests with Sidak's post-hoc for (A-D) and Mann-Whitney test for (E,F). Indicated value of $p$ represents the difference for the "culture medium" factor. ${ }^{*} p \leq 0.05$ (post-hoc corrected value of $p$ ). See also Supplementary Figure 1. 
A

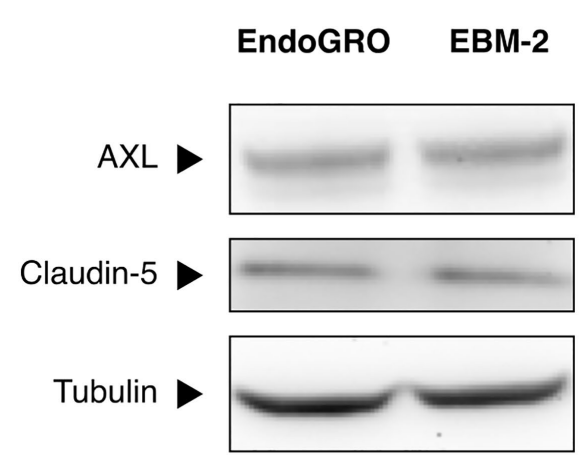

C

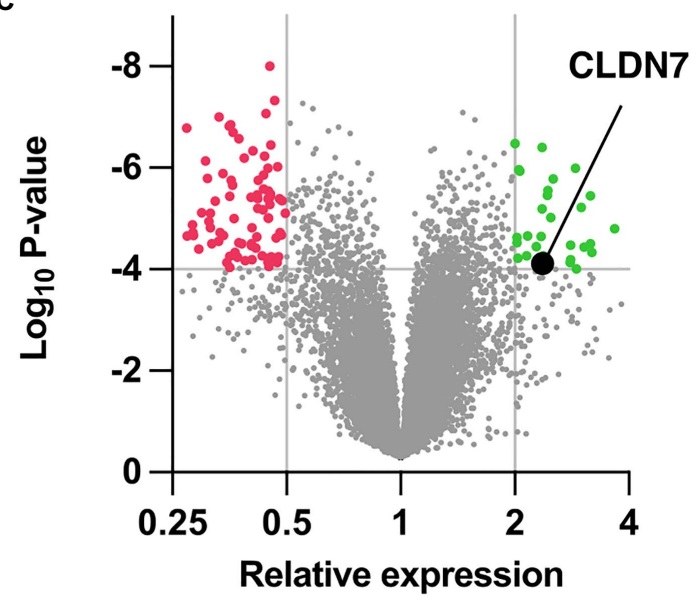

B

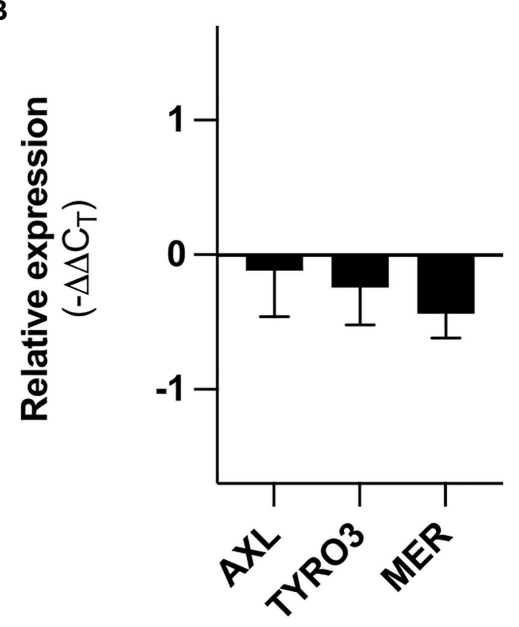

D

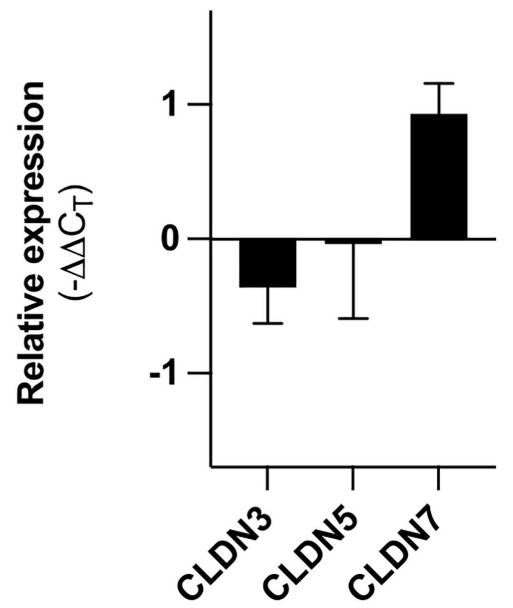

FIGURE 2 | Differential gene expression in hCMEC/D3 depending on culture medium. (A) hCMEC/D3 cells were cultured in EndoGRO or EBM-2, and cell lysates were processed by western blot for studying expression levels of $A X L$ and claudin-5. $\alpha$-Tubulin serves as loading control. (B) hCMEC/D3 cells were cultured in EndoGRO or EBM-2, and mRNA levels for AXL, TYRO3, and MERTK in EndoGRO relative to EBM-2 were quantified ( $n=4$ independent experiments). (C) hCMEC/ D3 cells were cultured in EndoGRO or EBM-2, and mRNA was processed on an Affymetrix GeneChip Human Gene 2.0ST ( $n=3$ independent experiments). The volcano plot presents the relative expression change of human genes in EndoGRO relative to EBM-2 and the statistical significance of the change. Thresholds (displayed as grey lines): $p<10^{-4}$, relative expression $<0.5$ and relative expression $>2$. (D) hCMEC/D3 cells were cultured in EndoGRO or EBM-2, and mRNA levels for CLDN3, CLDN5, and CLDN7 in EndoGRO relative to EBM-2 were quantified ( $n=4$ independent experiments). Data are presented as mean \pm SEM.

protein level, CLDN5 expression was comparable in the different conditions (Figure 2A).

\section{Downregulation of Claudin-7 Reduces hCMEC/D3 Susceptibility to ZIKV Infection}

We hypothesized that the ability of ZIKV to replicate more efficiently in cells grown in the EndoGRO medium, as compared to cells grown in EBM-2, could be (at least partially) due to differences in CLDN7 expression levels.

To test the impact of CLDN7 knockdown (KD) on hCMEC/ D3 susceptibility to African ZIKV infection, hCMEC/D3 cells were transduced with lentiviral vectors expressing shRNA sequences targeting CLDN7 or, as controls, CLDN5 transcripts or non-targeting shRNAs (CTRL). Transduced cells were selected over 2 weeks by puromycin treatment. The obtained cultures were a mix of populations of transduced cells.

As CLDN7 cannot be detected by western blot in hCMEC/ D3 cells (Supplementary Figure 3), Knockdown was validated by RT-qPCR on cellular mRNA (Supplementary Figure 4). As half-life of claudins is short (6-12 h; Van Itallie et al., 2019), one can assume that a significant reduction in claudin mRNA leads to reduced protein levels. Of note, CLDN5 seems consistently overexpressed in the CLDN7-KD cells (Supplementary Figure 4).

Transduction per se had no significant impact on hCMEC/ D3 susceptibility (i.e., production of viral RNA and infectious particles) to ZIKV since hCMEC/D3 cells transduced with a lentiviral vector expressing a control shRNA (CTRL) were as susceptible as non-transduced (WT) hCMEC/D3 cells (Figures $3 \mathbf{A}, \mathbf{B})$. KD of CLDN5 did not alter viral replication 
A

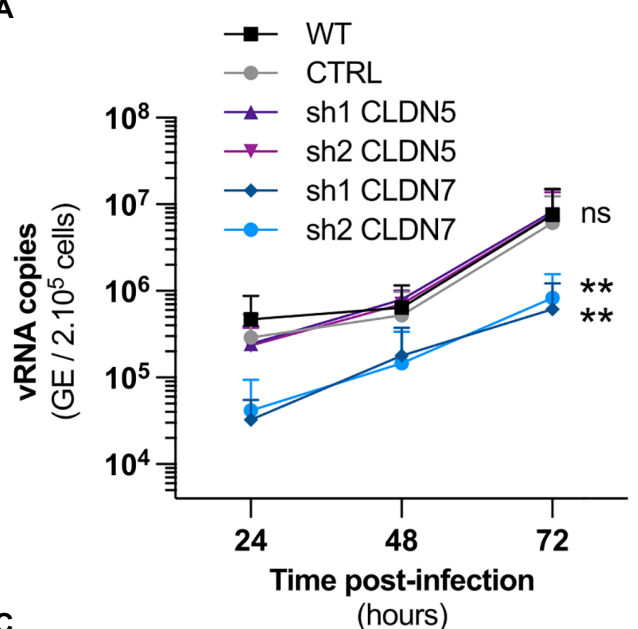

C

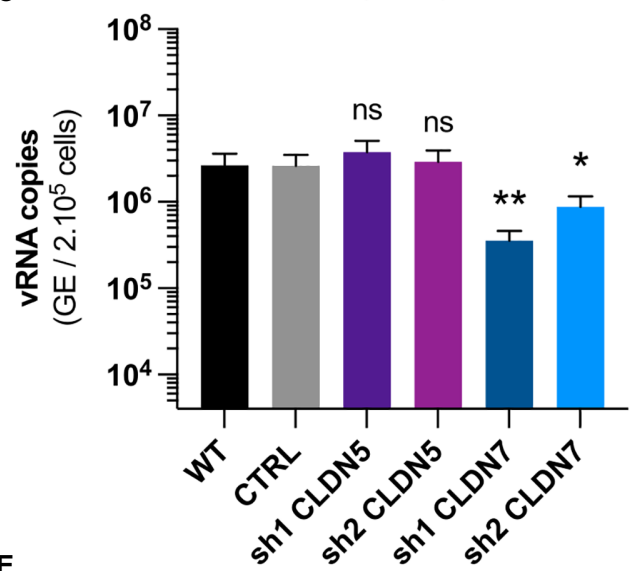

B
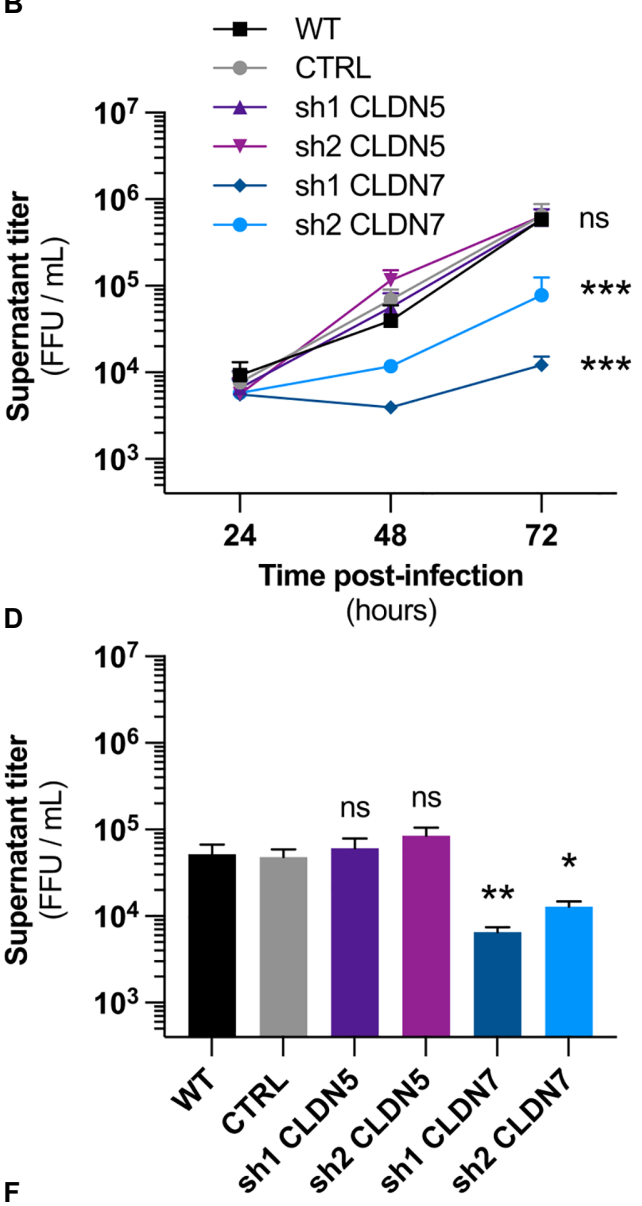

$\mathbf{F}$
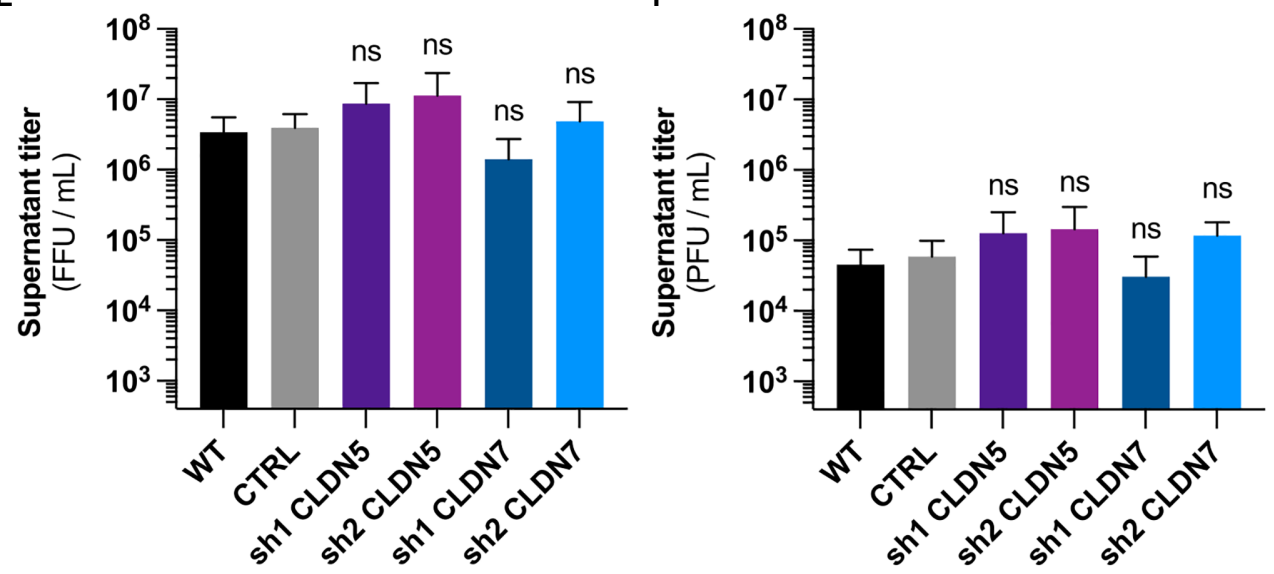

FIGURE 3 | CLDN7-Knockdown alters hCMEC/D3 susceptibility to ZIKV infection. The hCMEC/D3 cells were transduced with lentivectors containing shRNAs targeting CLDN5 and CLDN7 transcripts or a non-targeting control shRNA (CTRL). (A) Time-course quantification of viral RNA through RT-qPCR in transduced hCMEC/D3 cells infected with HD78788 ZIKV at a MOI of $1[n=3$ independent experiments, $p=0.03$ (2-Way ANOVA, Sidak's post-hoc)]. (B) Time-course quantification of viral production in the supernatant in transduced hCMEC/D3 cells infected with HD78788 ZIKV at a MOI of 1 [ $n=3$ independent experiments, $p=0.01$ (2-Way ANOVA, Sidak's post-hoc)]. (C) Quantification at 72h post-infection of viral RNA through RT-qPCR in transduced hCMEC/D3 cells infected with INMI1 ZIKV at a MOI of 1 [ $n=6$ independent experiments, $p<0.0001$ (Friedman test, Dunn's post-hoc)]. (D) Quantification at $72 \mathrm{~h}$ post-infection of viral production in the supernatant in transduced hCMEC/D3 cells infected with INMI1 ZIKV at a MOI of 1 [ $n=6$ independent experiments, $p<0.0001$ (Friedman test, Dunn's post-hoc)]. (E) Quantification at 48h post-infection of viral production in the supernatant in transduced hCMEC/D3 cells infected with RP9 JEV at a MOI of 1 [ $n=3$ independent experiments, $p=0.07$ (Friedman test, Dunn's post-hoc)]. (F) Quantification at $48 \mathrm{~h}$ post-infection of viral production in the supernatant in transduced hCMEC/D3 cells infected with 17D YFV at a MOI of 1 [ $n=3$ independent experiments, $p<0.001$ (Friedman test, Dunn's post-hoc)]. Each experiment was performed in triplicate. Data are presented as mean \pm SEM. ${ }^{* \star *} p \leq 0.001 ;{ }^{* *} p \leq 0.01 ;{ }^{*} p \leq 0.05 ; n s, p>0.05$ (post-hoc corrected value of $p$ ). See also Supplementary Figure 4. 
and production (Figures 3A,B). In contrast, viral replication and production were significantly reduced in CLDN7-KD cells, as compared to control cells (Figures $\mathbf{3 A}, \mathbf{B}$ ). CLDN7 expression was also required for optimal replication of the Brazilian strain of ZIKV (Figures 3C,D), as shown by RT-qPCR analysis.

Together these data demonstrate that CLDN7 expression favors ZIKV infection in hCMEC/D3 cells. Importantly, Japanese encephalitis and yellow fever viruses, both closely related to ZIKV, were replicating as efficiently in control hCMEC/D3 cells than in CLDN7-KD cells (Figures 3E,F). This demonstrates that CLDN7 is specifically involved in hCMEC/D3 susceptibility to ZIKV infection.

\section{Claudin-7 KD Reduced Susceptibility to ZIKV Infection of Endothelial Cells, but Not Epithelial Cells}

We evidenced the contribution of CLDN7 in ZIKV replication in hCMEC/D3 cells. We examined whether CLDN7 was also favoring ZIKV infection in two other endothelial cell lines: bone marrow endothelial cells (TrHBMEC) and umbilical vein endothelial cells (HUVEC). We also tested the effect of silencing CLDN7 expression in two epithelial cell lines: alveolar basal cells (A549) and embryonic kidney cells (HEK 293T).

Knockdown efficiency was validated by RT-qPCR in these four cell lines (Supplementary Figures 5A-D). We considered only cells with a $-\Delta \Delta C_{\mathrm{T}}$ (compared to WT cells) lower than -2; for HUVEC and HEK 293T, only one shRNA-derived cell line (out of five tested) was considered for further analysis (Supplementary Figures 5A-D). For epithelial cells, downregulation was validated at the protein level by western blot analysis (Supplementary Figures 5E,F).

We found that downregulation of CLDN7 significantly reduced infectious particle production in both endothelial cell types, TrHBMEC (Figure 4A) and HUVEC (Figure 4B). In contrast, no significant difference in viral yield was observed upon CLDN7-KD in A549 (Figure 4C) and HEK 293T epithelial cells (Figure 4D). Likewise, viral RNA production was significantly reduced in CLDN7-KD endothelial cells as compared to control cells (Figures 4E,F) but not in epithelial cells (Figures 4G,H).

Our data demonstrate that CLDN7 favors ZIKV replication in endothelial cells but not in epithelial cells.

\section{Claudin-7 Is Not Involved in the Early Steps of the Viral Cycle}

We next assessed which step of the viral cycle required the expression of CLDN7. To determine whether CLDN7 could be involved in viral adsorption to the cell membrane, hCMEC/ D3 cells were infected with ZIKV for $1 \mathrm{~h}$ at $4^{\circ} \mathrm{C}$, which allows viral binding but prevents virus internalization. Unbound viruses were then removed through extensive washing. ZIKV RNA levels, corresponding to virions that remained attached to cell membranes, were quantified by RT-qPCR analysis. As expected, more viral particles were bound to the cells when incubated at a MOI of 10 than at a MOI of 1 (Figures $\mathbf{5 A}, \mathbf{B}$ ). However, no difference in viral RNA yield was detected between WT and CLDN7-KD cells, suggesting that CLDN7 is dispensable for ZIKV binding to cell membranes.

We next tested whether CLDN7 was involved in virus internalization. Following a $1 \mathrm{~h}$ incubation at $4^{\circ} \mathrm{C}$, cells were cultured at $37^{\circ} \mathrm{C}$ for $2 \mathrm{~h}$. Cells were treated with trypsin to remove non-internalized viral particles. Quantification of intracellular ZIKV RNA present in the cells, representing internalized particles, showed no significant difference between the control cells and CLDN7-KD hCMEC/D3 cells at MOI 1 and 10 (Figures $\mathbf{5 C}, \mathbf{D}$ ), suggesting that CLDN7 does not contribute to ZIKV internalization.

The proportion of infected hCMEC/D3 cells was determined using staining against the viral non-structural protein NS1 at $16 \mathrm{~h}$ post-infection, and a time that corresponds to a unique replication cycle (Figures 5E, 6). At a MOI of 1, around $11 \%$ hCMEC/D3 cells were expressing the NS1 protein. In contrast, in CLDN7-KD cells, only around $4 \%$ of cells were positive for NS1, independently of the shRNA that was used. These data confirm our previous RT-qPCR and titration analyses (Figure 3) and thus further validate the role of CLDN7 as a proviral factor in endothelial cells. Of note, the distribution of NS1 was comparable in infected WT and CLDN7-KD cells (Figure 6).

Together these results demonstrate that CLDN7 downregulation does not affect viral attachment or internalization but reduces the number of cells expressing the viral protein NS1, suggesting that CLDN7 facilitates viral replication at a post-entry stage but prior to viral protein translation.

\section{DISCUSSION}

Since its emergence in the Pacific Islands and the Americas in 2015 , ZIKV is classified as a neurotropic virus. Numerous reports have evidenced its neuroinvasion and neurovirulence abilities. The access of ZIKV to the CNS purportedly requires productive infection of BBB endothelial cells (Liu et al., 2010; Mladinich et al., 2017; Papa et al., 2017; Cle et al., 2020).

We confirmed that human $\mathrm{BBB}$ endothelial cells are susceptible to ZIKV infection (Liu et al., 2010; Mladinich et al., 2017; Papa et al., 2017; Cle et al., 2020). There are two commercially available media for the culture of cerebral endothelial cell. Intriguingly, we found that hCMEC/D3 cells were more susceptible to viral infection when cultured in EndoGRO than in EBM-2. We found that differences in susceptibility are likely due to medium-induced changes in the expression profile of hCMEC/D3. Microarray analysis revealed that cells cultured in EndoGRO expressed significantly more CLDN7 than cells grown in EBM-2.

Although the complete composition of the media is not available, we know that EBM-2 is supplemented with bFGF while EndoGRO is supplemented with rhEGF. As previous papers have shown that epithelial cells overexpress CLDN7 upon EGF stimulation (Borok et al., 1996; Chen et al., 2005; Ferretti et al., 2017), we could hypothesize that CLDN7 overexpression may be, at least partially, due to the presence of rhEGF in EndoGRO. However, the transcriptomic differences 


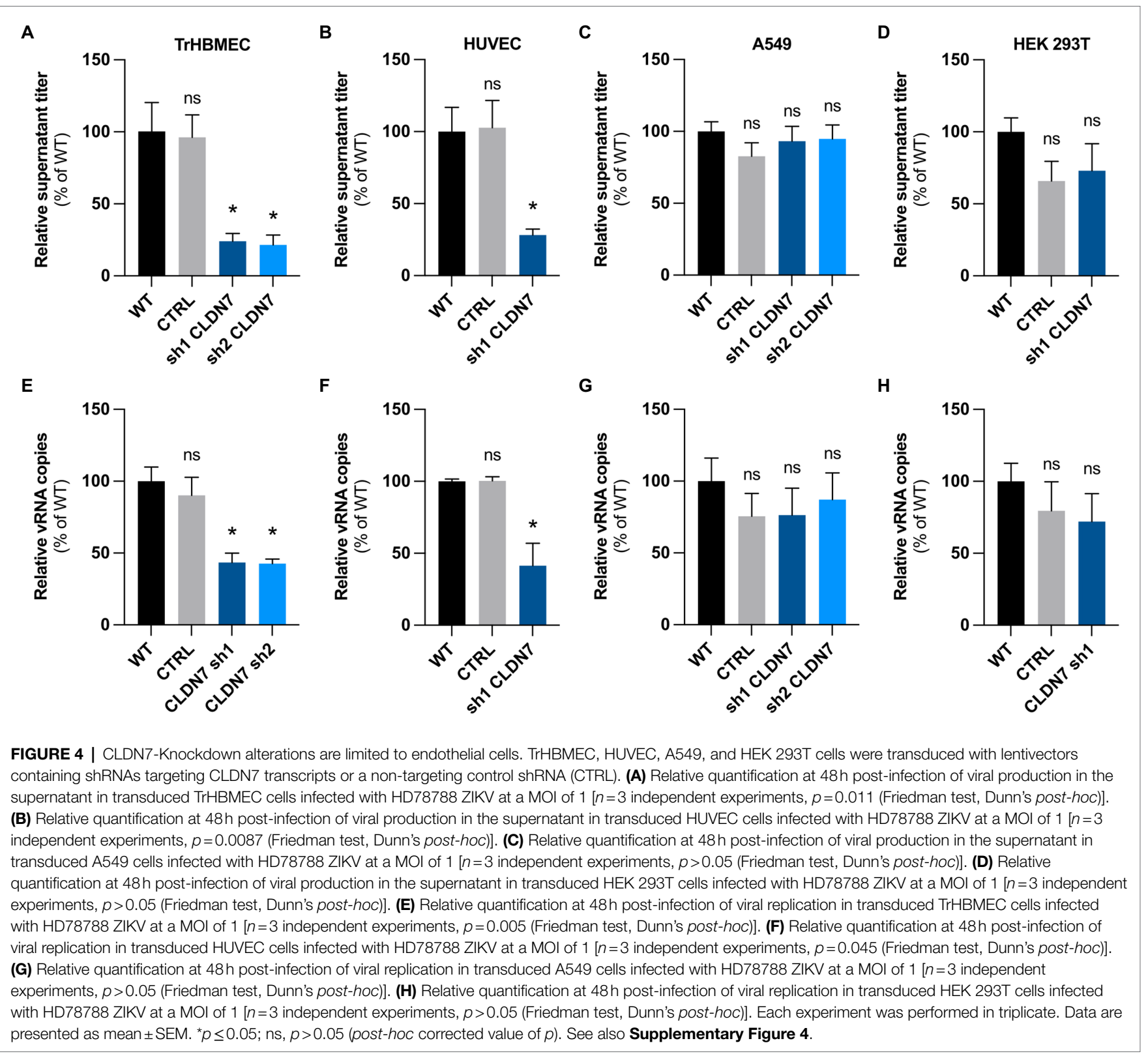

(Supplementary Tables 3 and 4) cannot be fully attributed to the differences between EGF and FGF signaling: functional enrichment analysis using the software FunRich 3.1.3 did not evidenced a significant EGF-related signature. Other elements in the media likely participate in media-induced transcriptomic differences.

As reported in other studies, we found that CLDN7 protein expression was not detectable using western blot analysis and commercially available antibodies (Vu et al., 2009). Thus, we used CLDN7 mRNA abundance as a proxy for CLDN7 expression. Stable shRNA-mediated CLDN7 downregulation impaired ZIKV replication in hCMEC/D3 cells and two other endothelial cell lines (i.e., HUVEC and HBMEC cells). However, the differential expression of CLDN7 may not solely explain the differences in susceptibility observed between the cells grown in the two media. Indeed, the replication curves between CLDN7-KD cells and cells cultured in EBM-2 are not comparable at a MOI of 1 (Figure 1A vs. Figure 3A). Other cellular factors (as detected in the microarray) are thus likely to be at play and contribute to the differences in viral susceptibility.

The importance of claudins in the infection of other members of the Flaviviridae family has been previously reported (Colpitts and Baumert, 2017). In particular, CLDN1 is a major entry receptor for both $\mathrm{HCV}$ and dengue viruses in hepatocytes (Evans et al., 2007). Claudins form a large family of 24 members that are differentially expressed across tissues (Krause et al., 2008). There could be some redundancy between claudins as viruses might be able to interact with a variety of them. For instance, HCV can use CLDN6 and 

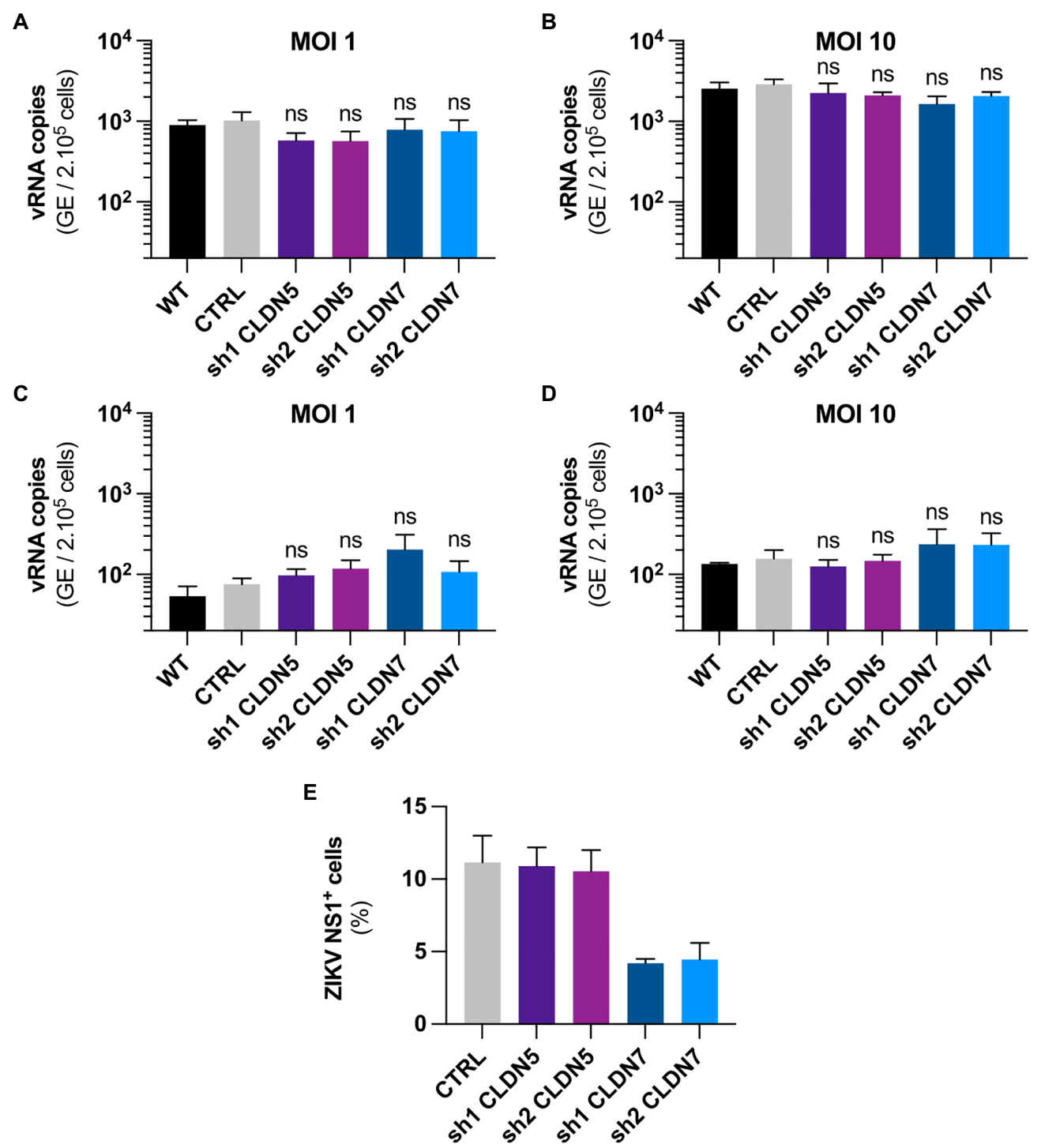

FIGURE 5 | CLDN7-Knockdown does not alter the early steps of ZIKV cycle. The hCMEC/D3 cells were transduced with lentivectors containing shRNAs targeting CLDN5 and CLDN7 transcripts or a non-targeting control shRNA (CTRL). (A,B) Binding of HD78788 ZIKV to transduced hCMEC/D3 cells, quantification of viral RNA through RT-qPCR in cells culture with the virus for $1 \mathrm{~h}$ at $4^{\circ} \mathrm{C}$ and extensively washed. (A) Cells were infected at a MOI of 1 [ $n=3$ independent experiments, $p>0.05$ (Friedman test, Dunn's post-hoc)]. (B) Cells were infected at a MOI of 10 [ $n=5$ independent experiments, $p>0.05$ (Friedman test, Dunn's post-hoc)]. (C,D) Internalization of HD78788 ZIKV in transduced hCMEC/D3 cells, quantification of viral RNA through RT-qPCR in cells from the binding assay furthermore kept for $2 \mathrm{~h}$ at $37^{\circ} \mathrm{C}$ followed by removal of un-internalized virions. (C) Cells were infected at a MOI of 1 [ $n=3$ independent experiments, $p>0.05$ (Friedman test, Dunn's posthoc)]. (D) Cells were infected at a MOI of 10 [ $n=3$ independent experiments, $p>0.05$ (Friedman test, Dunn's post-hoc)]. (E) Transduced hCMEC/D3 cells were infected with a MOI of 1 and kept for $16 \mathrm{~h}$ to allow the virus to complete one replication cycle. Cells were stained with anti-NS1 antibodies and DAPI. ZIKV NS1positive hCMEC/D3 cells were quantified ( $n=2$ independent experiments). Each experiment was performed in triplicate. Data are presented as mean $\pm \mathrm{SEM}$. ns, $p>0.05$ (post-hoc corrected value of $p$ ).

CLDN9 as alternative receptors to CLDN1 (Meertens et al., 2008). Such redundancy may explain why KD of CLDN7 in epithelial cells had no impact on viral replication. These cells express many claudins, which may substitute CLDN7. The nature of the claudins used by ZIKV may thus be celltype or tissue specific.

Viral infection is carried out through several distinct steps. First, the virus is adsorbed at the cell surface, which is mediated by the interaction of the viral envelope with HSPG or C-type lectin receptors, such as DC-SIGN (Hamel et al., 2015; Kim et al., 2017). Different internalization paths have been proposed for ZIKV. For instance, the AXL-dependent internalization would mimic the internalization of apoptotic bodies (Meertens et al., 2017). Internalization could also occur upon usage of integrins (Wang et al., 2020), sialic-acids (Tan et al., 2019), or HSP70 (Pujhari et al., 2019). It is unclear whether viruses that exploit these different receptors end up in the same endosomal compartment or whether their fate depends on 

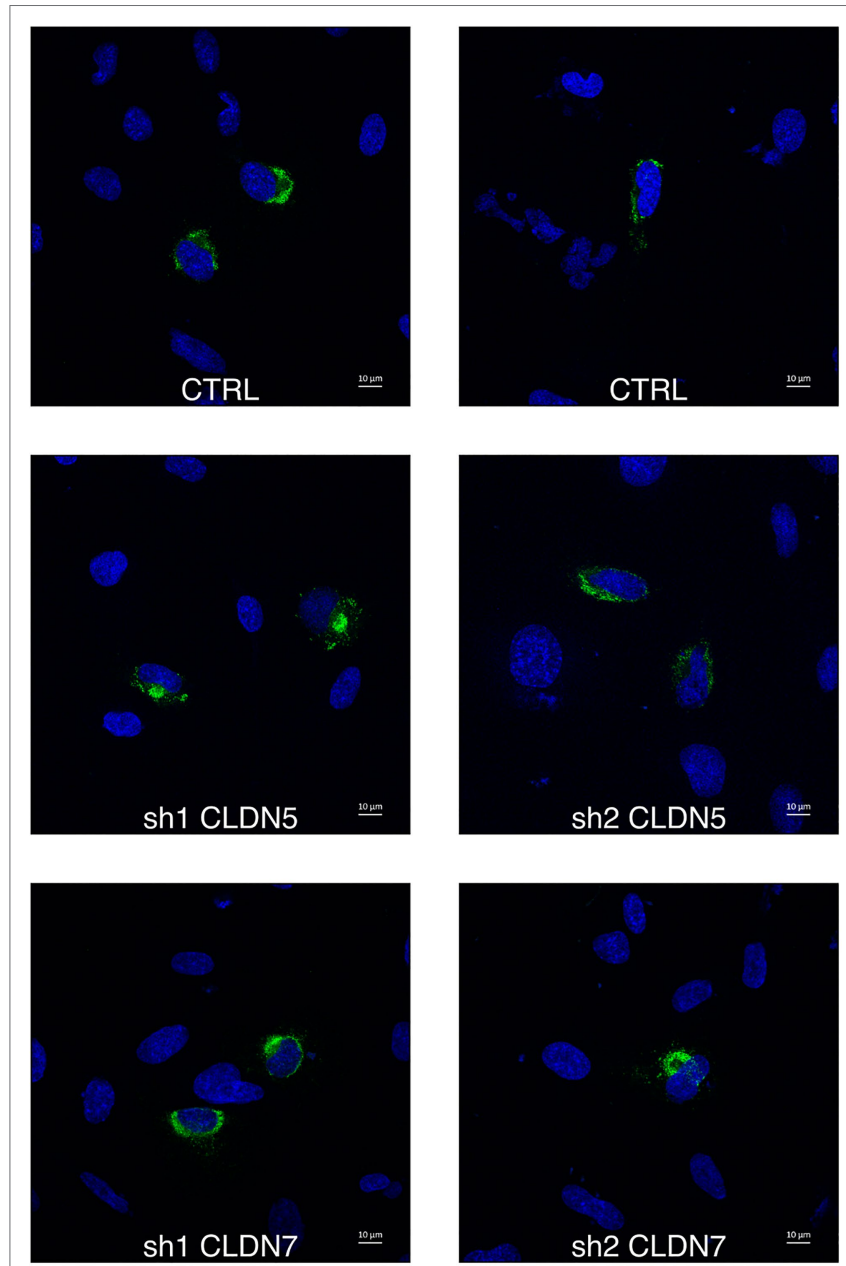

FIGURE 6 | CLDN7-Knockdown does not alter ZIKV infection phenotype. The hCMEC/D3 cells were transduced with lentivectors containing shRNAs targeting CLDN5 and CLDN7 transcripts or a non-targeting control shRNA (CTRL). Transduced hCMEC/D3 cells were infected with ZIKV at a MOI of 1 and kept for $16 \mathrm{~h}$ to allow the virus to complete one replication cycle. Confocal analysis of cells stained with anti-NS1 antibodies (green) and DAPI (blue). Representative images of ZIKV infected hCMEC/D3 cells.

receptor usage, as suggested for related yellow fever viruses (Fernandez-Garcia et al., 2016). We show that CLDN7-KD does not affect ZIKV adsorption or internalization in endothelial cells.

By immunofluorescence analysis, we found that NS1 protein localization was comparable between CTRL and CLDN7-KD infected cells. This suggests that CLDN7 is not necessary for the establishment of effective replication sites in the cell. Indeed, if CLDN7 was part of the replication site, we would expect alterations in their perinuclear organization, as found for instance for Atlastin-3 (Monel et al., 2019).

Our data point to a role of CLDN7 anywhere between internalization and RNA production. It could for instance have a direct role in the fusion of the viral envelope with the endosomal membrane, as evidenced for occludin in the context of HCV infection (Benedicto et al., 2009). It could also have a more indirect function, such as regulating viral trafficking within endosomal compartments. Unfortunately, subcellular colocalization of CLDN7 and the virus could not be investigated in our system, as endogenous CLDN7 was not detectable by immunofluorescence.

In conclusion, we have found that CLDN7 is a susceptibility factor to ZIKV infection in endothelial cells. This finding provides functional insights into the mechanisms leading to ZIKV susceptibility in human endothelial cells in vivo and may be subsequently used as a novel target for antiviral drug development to prevent BBB disruption associated with ZIKVrelated neurological disorders.

\section{DATA AVAILABILITY STATEMENT}

The datasets presented in this study can be found in online repositories. The names of the repository/repositories and accession number(s) can be found in the article/ Supplementary Material.

\section{AUTHOR CONTRIBUTIONS}

JZ, VL, and PA conceived the study. P-EC, AG, and PA obtained funding. JZ, PJ, MC, and PA performed experiments. VL and NP provided viruses. JZ and PA wrote the manuscript. All authors contributed to the article and approved the submitted version.

\section{FUNDING}

This work was supported by a Pasteur-Fiocruz grant and the "Investissement d'Avenir" as part of a "Laboratoire d'Excellence" (LabEx) French research program: Integrative Biology of Emerging Infectious Diseases (ANR10-LBX-62 IBEID). JZ was the recipient of a PhD fellowship from the ED562 - BioSPC and French ministry of education and research. VL was supported by a fellowship from the "Fondation pour la Recherche Médicale" (FRM).

\section{ACKNOWLEDGMENTS}

Microarray was performed by the Plateforme GenomEast of IGBMC, Illkirch, France. NS1 antibody was a kind gift from Marie Flamand (Institut Pasteur, Paris).

\section{SUPPLEMENTARY MATERIAL}

The Supplementary Material for this article can be found online at: https://www.frontiersin.org/articles/10.3389/fmicb.2021. 746589/full\#supplementary-material 


\section{REFERENCES}

Amara, A., and Mercer, J. (2015). Viral apoptotic mimicry. Nat. Rev. Microbiol. 13, 461-469. doi: 10.1038/nrmicro3469

Ayala-Nunez, N. V., Follain, G., Delalande, F., Hirschler, A., Partiot, E., Hale, G. L., et al. (2019). Zika virus enhances monocyte adhesion and transmigration favoring viral dissemination to neural cells. Nat. Commun. 10:4430. doi: 10.1038/s41467-019-12408-x

Ballabh, P., Braun, A., and Nedergaard, M. (2004). The blood-brain barrier: an overview: structure, regulation, and clinical implications. Neurobiol. Dis. 16, 1-13. doi: 10.1016/j.nbd.2003.12.016

Benedicto, I., Molina-Jimenez, F., Bartosch, B., Cosset, F. L., Lavillette, D., Prieto, J., et al. (2009). The tight junction-associated protein occludin is required for a postbinding step in hepatitis $\mathrm{C}$ virus entry and infection. $J$. Virol. 83, 8012-8020. doi: 10.1128/JVI.00038-09

Borok, Z., Hami, A., Danto, S. I., Lubman, R. L., Kim, K. J., and Crandall, E. D. (1996). Effects of EGF on alveolar epithelial junctional permeability and active sodium transport. Am. J. Phys. 270(4 Pt 1), L559-L565. doi: 10.1152/ ajplung.1996.270.4.L559

Bramley, J. C., Drummond, C. G., Lennemann, N. J., Good, C. A., Kim, K. S., and Coyne, C. B. (2017). A three-dimensional cell culture system to model RNA virus infections at the blood-brain barrier. mSphere 2:e00206-17. doi: 10.1128/mSphere.00206-17

Cao-Lormeau, V. M., Blake, A., Mons, S., Lastere, S., Roche, C., Vanhomwegen, J., et al. (2016). Guillain-Barre syndrome outbreak associated with Zika virus infection in French Polynesia: a case-control study. Lancet 387, 1531-1539. doi: 10.1016/S0140-6736(16)00562-6

Carteaux, G., Maquart, M., Bedet, A., Contou, D., Brugieres, P., Fourati, S., et al. (2016). Zika virus associated with meningoencephalitis. N. Engl. J. Med. 374, 1595-1596. doi: 10.1056/NEJMc1602964

Cauchemez, S., Besnard, M., Bompard, P., Dub, T., Guillemette-Artur, P., Eyrolle-Guignot, D., et al. (2016). Association between Zika virus and microcephaly in French Polynesia, 2013-15: a retrospective study. Lancet 387, 2125-2132. doi: 10.1016/S0140-6736(16)00651-6

Chang, C. Y., Li, J. R., Chen, W. Y., Ou, Y. C., Lai, C. Y., Hu, Y. H., et al. (2015). Disruption of in vitro endothelial barrier integrity by Japanese encephalitis virus-infected astrocytes. Glia 63, 1915-1932. doi: 10.1002/ glia.22857

Chen, J., Yang, Y. F., Yang, Y., Zou, P., Chen, J., He, Y., et al. (2018). AXL promotes Zika virus infection in astrocytes by antagonizing type I interferon signalling. Nat. Microbiol. 3, 302-309. doi: 10.1038/s41564-017-0092-4

Chen, S. P., Zhou, B., Willis, B. C., Sandoval, A. J., Liebler, J. M., Kim, K. J., et al. (2005). Effects of transdifferentiation and EGF on claudin isoform expression in alveolar epithelial cells. J. Appl. Physiol. 98, 322-328. doi: 10.1152/japplphysiol.00681.2004

Cle, M., Desmetz, C., Barthelemy, J., Martin, M. F., Constant, O., Maarifi, G., et al. (2020). Zika virus infection promotes local inflammation, cell adhesion molecule upregulation, and leukocyte recruitment at the blood-brain barrier. MBio 11:e01183-20. doi: 10.1128/mBio.01183-20

Coller, K. E., Berger, K. L., Heaton, N. S., Cooper, J. D., Yoon, R., and Randall, G. (2009). RNA interference and single particle tracking analysis of hepatitis C virus endocytosis. PLoS Pathog. 5:e1000702. doi: 10.1371/journal.ppat.1000702

Colpitts, C. C., and Baumert, T. F. (2017). Claudins in viral infection: from entry to spread. Pflugers Arch. 469, 27-34. doi: 10.1007/s00424-016-1908-4

de Carvalho, G. C., Borget, M. Y., Bernier, S., Garneau, D., da Silva Duarte, A. J., and Dumais, N. (2019). RAGE and CCR7 mediate the transmigration of Zika-infected monocytes through the blood-brain barrier. Immunobiology 224, 792-803. doi: 10.1016/j.imbio.2019.08.007

Dejarnac, O., Hafirassou, M. L., Chazal, M., Versapuech, M., Gaillard, J., Perera-Lecoin, M., et al. (2018). TIM-1 ubiquitination mediates dengue virus entry. Cell Rep. 23, 1779-1793. doi: 10.1016/j.celrep.2018.04.013

Dick, G. W., Kitchen, S. F., and Haddow, A. J. (1952). Zika virus. I. Isolations and serological specificity. Trans. R. Soc. Trop. Med. Hyg. 46, 509-520.

Evans, M. J., von Hahn, T., Tscherne, D. M., Syder, A. J., Panis, M., Wolk, B., et al. (2007). Claudin-1 is a hepatitis $\mathrm{C}$ virus co-receptor required for a late step in entry. Nature 446, 801-805. doi: 10.1038/nature05654

Fernandez-Garcia, M. D., Meertens, L., Chazal, M., Hafirassou, M. L., Dejarnac, O., Zamborlini, A., et al. (2016). Vaccine and wild-type strains of yellow fever virus engage distinct entry mechanisms and differentially stimulate antiviral immune responses. MBio 7:e01956-15. doi: 10.1128/mBio.01956-15

Ferretti, E., Tremblay, E., Thibault, M. P., Grynspan, D., Burghardt, K. M., Bettolli, M., et al. (2017). The nitric oxide synthase 2 pathway is targeted by both pro- and anti-inflammatory treatments in the immature human intestine. Nitric Oxide 66, 53-61. doi: 10.1016/j.niox.2017.03.003

Gao, F., Duan, X., Lu, X., Liu, Y., Zheng, L., Ding, Z., et al. (2010). Novel binding between pre-membrane protein and claudin-1 is required for efficient dengue virus entry. Biochem. Biophys. Res. Commun. 391, 952-957. doi: 10.1016/j.bbrc.2009.11.172

Hamel, R., Dejarnac, O., Wichit, S., Ekchariyawat, P., Neyret, A., Luplertlop, N., et al. (2015). Biology of Zika virus infection in human skin cells. J. Virol. 89, 8880-8896. doi: 10.1128/JVI.00354-15

Hastings, A. K., Yockey, L. J., Jagger, B. W., Hwang, J., Uraki, R., Gaitsch, H. F., et al. (2017). TAM receptors are not required for Zika virus infection in mice. Cell Rep. 19, 558-568. doi: 10.1016/j.celrep.2017.03.058

Kim, S. Y., Zhao, J., Liu, X., Fraser, K., Lin, L., Zhang, X., et al. (2017). Interaction of Zika virus envelope protein with glycosaminoglycans. Biochemistry 56, 1151-1162. doi: 10.1021/acs.biochem.6b01056

Krause, G., Winkler, L., Mueller, S. L., Haseloff, R. F., Piontek, J., and Blasig, I. E. (2008). Structure and function of claudins. Biochim. Biophys. Acta 1778, 631-645. doi: 10.1016/j.bbamem.2007.10.018

Leda, A. R., Bertrand, L., Andras, I. E., El-Hage, N., Nair, M., and Toborek, M. (2019). Selective disruption of the blood-brain barrier by Zika virus. Front. Microbiol. 10:2158. doi: 10.3389/fmicb.2019.02158

Liang, J. J., Liao, C. L., Liao, J. T., Lee, Y. L., and Lin, Y. L. (2009). A Japanese encephalitis virus vaccine candidate strain is attenuated by decreasing its interferon antagonistic ability. Vaccine 27, 2746-2754. doi: 10.1016/j. vaccine.2009.03.007

Liu, S., DeLalio, L. J., Isakson, B. E., and Wang, T. T. (2016). AXL-mediated productive infection of human endothelial cells by Zika virus. Circ. Res. 119, 1183-1189. doi: 10.1161/CIRCRESAHA.116.309866

Liu, S. F., Kuo, W., Yang, W., Liu, W. Q., Gibson, G. A., Dorko, K., et al. (2010). The second extracellular loop dictates occludin-mediated HCV entry. Virology 407, 160-170. doi: 10.1016/j.virol.2010.08.009

Mecharles, S., Herrmann, C., Poullain, P., Tran, T. H., Deschamps, N., Mathon, G., et al. (2016). Acute myelitis due to Zika virus infection. Lancet 387:1481 doi: 10.1016/S0140-6736(16)00644-9

Medigeshi, G. R., Hirsch, A. J., Brien, J. D., Uhrlaub, J. L., Mason, P. W., Wiley, C., et al. (2009). West nile virus capsid degradation of claudin proteins disrupts epithelial barrier function. J. Virol. 83, 6125-6134. doi: 10.1128/ JVI.02617-08

Meertens, L., Bertaux, C., Cukierman, L., Cormier, E., Lavillette, D., Cosset, F. L., et al. (2008). The tight junction proteins claudin-1, -6 , and -9 are entry cofactors for hepatitis C virus. J. Virol. 82, 3555-3560. doi: 10.1128/JVI.01977-07

Meertens, L., Labeau, A., Dejarnac, O., Cipriani, S., Sinigaglia, L., Bonnet-Madin, L., et al. (2017). Axl mediates ZIKA virus entry in human glial cells and modulates innate immune responses. Cell Rep. 18, 324-333. doi: 10.1016/j. celrep.2016.12.045

Mladinich, M. C., Schwedes, J., and Mackow, E. R. (2017). Zika virus persistently infects and is basolaterally released from primary human brain microvascular endothelial cells. MBio 8:e00952-17. doi: 10.1128/mBio.00952-17

Monel, B., Rajah, M. M., Hafirassou, M. L., Sid Ahmed, S., Burlaud-Gaillard, J., Zhu, P. P., et al. (2019). Atlastin endoplasmic reticulum-shaping proteins facilitate Zika virus replication. J. Virol. 93:e01047-19. doi: 10.1128/JVI.01047-19

Mustafa, Y. M., Meuren, L. M., Coelho, S. V. A., and de Arruda, L. B. (2019). Pathways exploited by flaviviruses to counteract the blood-brain barrier and invade the central nervous system. Front. Microbiol. 10:525. doi: 10.3389/ fmicb.2019.00525

Obermeier, B., Verma, A., and Ransohoff, R. M. (2016). The blood-brain barrier. Handb. Clin. Neurol. 133, 39-59. doi: 10.1016/B978-0-444-63432-0.00003-7

Panganiban, A. T., Blair, R. V., Hattler, J. B., Bohannon, D. G., Bonaldo, M. C., Schouest, B., et al. (2020). A Zika virus primary isolate induces neuroinflammation, compromises the blood-brain barrier and upregulates CXCL12 in adult macaques. Brain Pathol. 30, 1017-1027. doi: 10.1111/ bpa. 12873

Papa, M. P., Meuren, L. M., Coelho, S. V. A., Lucas, C. G. O., Mustafa, Y. M., Lemos Matassoli, F., et al. (2017). Zika virus infects, activates, and crosses 
brain microvascular endothelial cells, without barrier disruption. Front. Microbiol. 8:2557. doi: 10.3389/fmicb.2017.02557

Pathan, M., Keerthikumar, S., Ang, C. S., Gangoda, L., Quek, C. Y., Williamson, N. A., et al. (2015). FunRich: an open access standalone functional enrichment and interaction network analysis tool. Proteomics 15, 2597-2601. doi: 10.1002/pmic.201400515

Pujhari, S., Brustolin, M., Macias, V. M., Nissly, R. H., Nomura, M., Kuchipudi, S. V., et al. (2019). Heat shock protein 70 (Hsp70) mediates Zika virus entry, replication, and egress from host cells. Emerg. Microbes Infect. 8, 8-16. doi: 10.1080/22221751.2018.1557988

Richard, A. S., Shim, B. S., Kwon, Y. C., Zhang, R., Otsuka, Y., Schmitt, K., et al. (2017). AXL-dependent infection of human fetal endothelial cells distinguishes Zika virus from other pathogenic flaviviruses. Proc. Natl. Acad. Sci. U. S. A. 114, 2024-2029. doi: 10.1073/pnas.1620558114

Roe, K., Kumar, M., Lum, S., Orillo, B., Nerurkar, V. R., and Verma, S. (2012). West Nile virus-induced disruption of the blood-brain barrier in mice is characterized by the degradation of the junctional complex proteins and increase in multiple matrix metalloproteinases. J. Gen. Virol. 93(Pt 6), 1193-1203. doi: 10.1099/vir.0.040899-0

Roze, B., Najioullah, F., Ferge, J. L., Apetse, K., Brouste, Y., Cesaire, R., et al. (2016). Zika virus detection in urine from patients with Guillain-Barre syndrome on Martinique, January 2016. Euro Surveill. 21:30154. doi: 10.2807/1560-7917.ES.2016.21.16.30205

Schrade, A., Sade, H., Couraud, P. O., Romero, I. A., Weksler, B. B., and Niewoehner, J. (2012). Expression and localization of claudins-3 and -12 in transformed human brain endothelium. Fluids Barriers CNS 9:6. doi: 10.1186/2045-8118-9-6

Schul, W., Liu, W., Xu, H. Y., Flamand, M., and Vasudevan, S. G. (2007). A dengue fever viremia model in mice shows reduction in viral replication and suppression of the inflammatory response after treatment with antiviral drugs. J. Infect. Dis. 195, 665-674. doi: 10.1086/511310

Schweitzer, K. M., Vicart, P., Delouis, C., Paulin, D., Drager, A. M., Langenhuijsen, M. M., et al. (1997). Characterization of a newly established human bone marrow endothelial cell line: distinct adhesive properties for hematopoietic progenitors compared with human umbilical vein endothelial cells. Lab. Investig. 76, 25-36.

Srivastava, M., Zhang, Y., Chen, J., Sirohi, D., Miller, A., Zhang, Y., et al. (2020). Chemical proteomics tracks virus entry and uncovers NCAM1 as Zika virus receptor. Nat. Commun. 11:3896. doi: 10.1038/s41467-020-17638-y

Tan, C. W., Huan Hor, C. H., Kwek, S. S., Tee, H. K., Sam, I. C., Goh, E. L. K., et al. (2019). Cell surface alpha2,3-linked sialic acid facilitates Zika virus internalization. Emerg. Microbes Infect. 8, 426-437. doi: 10.1080/22221751. 2019.1590130

Urich, E., Lazic, S. E., Molnos, J., Wells, I., and Freskgard, P. O. (2012). Transcriptional profiling of human brain endothelial cells reveals key properties crucial for predictive in vitro blood-brain barrier models. PLoS One 7:e38149. doi: 10.1371/journal.pone.0038149

Van Itallie, C. M., Lidman, K. F., Tietgens, A. J., and Anderson, J. M. (2019). Newly synthesized claudins but not occludin are added to the basal side of the tight junction. Mol. Biol. Cell 30, 1406-1424. doi: 10.1091/mbc. E19-01-0008

Vu, K., Weksler, B., Romero, I., Couraud, P. O., and Gelli, A. (2009). Immortalized human brain endothelial cell line HCMEC/D3 as a model of the bloodbrain barrier facilitates in vitro studies of central nervous system infection by Cryptococcus neoformans. Eukaryot. Cell 8, 1803-1807. doi: 10.1128/ EC.00240-09

Wang, Z. Y., Wang, Z., Zhen, Z. D., Feng, K. H., Guo, J., Gao, N., et al. (2017). Axl is not an indispensable factor for Zika virus infection in mice. J. Gen. Virol. 98, 2061-2068. doi: 10.1099/jgv.0.000886

Wang, X., Yang, Y., Yang, X., Liu, X., Wang, X., Gao, L., et al. (2021). Classical swine fever virus infection suppresses claudin-1 expression to facilitate its replication in PK-15 cells. Microb. Pathog. 157:105012. doi: 10.1016/j. micpath.2021.105012

Wang, S., Zhang, Q., Tiwari, S. K., Lichinchi, G., Yau, E. H., Hui, H., et al. (2020). Integrin alphavbeta5 internalizes Zika virus during neural stem cells infection and provides a promising target for antiviral therapy. Cell Rep. 30, 969.e964-983.e964. doi: 10.1016/j.celrep.2019.11.020

Weksler, B. B., Subileau, E. A., Perriere, N., Charneau, P., Holloway, K., Leveque, M., et al. (2005). Blood-brain barrier-specific properties of a human adult brain endothelial cell line. FASEB J. 19, 1872-1874. doi: 10.1096/ f.04-3458fje

Conflict of Interest: The authors declare that the research was conducted in the absence of any commercial or financial relationships that could be construed as a potential conflict of interest.

Publisher's Note: All claims expressed in this article are solely those of the authors and do not necessarily represent those of their affiliated organizations, or those of the publisher, the editors and the reviewers. Any product that may be evaluated in this article, or claim that may be made by its manufacturer, is not guaranteed or endorsed by the publisher.

Copyright (ㄷ 2021 Zoladek, Legros, Jeannin, Chazal, Pardigon, Ceccaldi, Gessain, Jouvenet and Afonso. This is an open-access article distributed under the terms of the Creative Commons Attribution License (CC BY). The use, distribution or reproduction in other forums is permitted, provided the original author(s) and the copyright owner(s) are credited and that the original publication in this journal is cited, in accordance with accepted academic practice. No use, distribution or reproduction is permitted which does not comply with these terms. 